\title{
Sutureless Hemorrhoidectomy Vs Open Hemorrhoidectomy: A Prospective Study in a Regional Hospital of Western Nepal
}

\author{
Ghimire P, * Gurung NV, ${ }^{1}$ Upadhaya PK, ${ }^{1}$ Shrestha $S,{ }^{1}$ Gurung $A,{ }^{1}$ Poudel SR ${ }^{1}$ \\ ${ }^{1}$ Department of Surgery, Western Regional Hospital, Pokhara, Nepal
}

\author{
*Corresponding Author: \\ Dr. Prajwal Ghimire MBBS MRCSEd. \\ Department of Surgery \\ Western Regional Hospital, Pokhara, Nepal \\ Email: prazgh@gmail.com
}

\begin{abstract}
Background: The aim of this study is to compare sutureless Hemorroidectomy with Conventional Open Hemorrhoidectomy in terms of safety and clinical efficacy.
\end{abstract}

Method: A prospective analytical study of 60 operated patients (a nonrandomized cohort) was carried out by following up from admission to 1 month period after hospital discharge in between July, 2013 to February, 2014 in Western Regional Hospital, Pokhara, Nepal. Demographic data, clinical data, mean operation time, duration of hospital stay, number of parenteral analgesic injections and post-operative complications between the two groups were recorded and analyzed.

Result: There were no statistically significant differences between the two groups in terms of age, gender, duration of symptoms, grade of the hemorrhoid(s), or number of hemorrhoids resected. The mean operating time for LigaSure sutureless hemorrhoidectomy was significantly shorter than that for the Open hemorrhoidectomy $(\mathrm{P}<0.001)$. Patients treated with the LigaSure technique had less blood loss, a better pain score $(\mathrm{P}<$ $0.001)$, less parenteral analgesic requirement $(\mathrm{P}<0.001)$, shorter hospital stay $(\mathrm{P}<0.001)$, and early return to work $(\mathrm{P}<0.01)$.

Conclusion: Sutureless Technique is safe and effective as compared to Conventional Open Hemorrhoidectomy for grade III and IV hemorrhoids.

Keywords: Hemorroidectomy; ligasure; open; sutureless

\section{Background:}

Hemorrohoidectomy remains the treatment of choice for symptomatic Grade III and IV Hemorrhoids. ${ }^{1}$ The traditional accepted methods are Milligan Morgan technique ${ }^{2}$ and Ferguson's technique. ${ }^{3}$ Recent methods are stapled haemorrhoidopexy, Harmonic Scalpel ${ }^{\mathrm{TM}}$ technique, Transanal haemorrhoidal dearterialisation and Ligasure ${ }^{\mathrm{TM}}$ technique. ${ }^{1}$ Stapler technique, dearterialisation technique and Harmonic Scalpel ${ }^{\mathrm{TM}}$ technique are expensive technique and beyond the reach of all patients. ${ }^{1}$ Recent studies from other parts of the world are increasingly supporting use of ligasure sutureless hemorrhoidectomy but its use cannot be unequivocally recommended for patients in countries like Nepal where the technical expertise and other factors may limit its use. The study was conducted to compare the conventional open technique with the new sutureless technique of hemorroidectomy in terms of clinical efficacy and safety in Nepal.

\section{Methods:}

A total of 60 patients (30 each in open hemorrhoidectomy and ligasure group) were included in the study after taking informed written consent. All cases with III and IV degree 
Hemorrhoids including thrombosed hemorrhoids were included in the study. Hemorrhoids secondary to other causes (IBD, Ca Rectum) were excluded from the study.

Patients coming to outpatient department were randomly assigned to the two groups irrespective of age, sex or degree of hemorrhoids.

\section{Surgical Technique:}

Under Spinal Anesthesia, patient was kept in Lithotomy position and initial dissection was done as per Milligan Morgan technique using mono-polar cautery. For the Ligasure group, this was followed by Pedicle excision using LigaSure Impact ${ }^{\mathrm{TM}}$ LF4200 Instrument connected to ForceTriad ${ }^{\mathrm{TM}}$ energy platform. For the Open Group, the pedicle was ligated with absorbable suture and excision done with monopolar cautery.

Post-Operative Management: Patient received postoperative parenteral injections of diclofenac $(75 \mathrm{mg} / 2 \mathrm{ml})$ and was advised for sitz bath twice a day from post-operative day 1 for 1 week.

Follow up: 2 weeks and 1 month

Statistical Method: Mean and number (\%) were presented for continuous and categorical variables, respectively. T test was used for analysis of the variables using IBM SPSS Statistics 20 Software. $\mathrm{P}$ values $<0.05$ were considered significant.

\section{Results:}

The mean age of patients undergoing Ligasure ${ }^{\mathrm{TM}}$ sutureless hemorrhoidectomy was 41 years $( \pm$ SD 11.3) (range 27-75 years) and for the Open hemorrhoidectomy group was 45 years ( \pm SD 10.9) (range 24-67 years). The male: female ratio was 2.7:1 in Ligasure and 2.3:1 in Open hemorrhoidectomy groups.

The mean operating time (excluding anesthesia administering time) in the Ligasure and Open hemorrhoidectomy groups was $7.6 \mathrm{~min}( \pm \mathrm{SD} 2.5)$ and $18.9 \mathrm{~min}( \pm \mathrm{SD} 4.5)$ respectively $(\mathrm{t}=12.17, \mathrm{p}<0.001)$. The VAS pain score in Ligasure group was $3.8 \pm 0.6$ and in the Open group was $7.4 \pm 0.7(t=19.3$, $\mathrm{p}<0.001$ ). Average number of parenteral injections given to the patients were $3 \pm 0.6$ in Ligasure group and $7 \pm 0.9$ in Open group $(\mathrm{t}=19.3, \mathrm{p}<0.001)$. In the early post- operative period, in the Ligasure group (30 patients) 1 patient had hemorrhage, 1 developed urinary retention.

In the Open group (30 patients) 10 patients $(33.33 \%$ ) had hemorrhage, $14(46.67 \%)$ developed urinary retention. The average postoperative stay in the Ligasure group was $1.03 \pm 0.1$ days and in the Open group was $2.13 \pm 0.5$ days $(\mathrm{t}=11.1, \mathrm{p}<0.001)$. None of our patients developed delayed complications like incontinence or anal stenosis. Average time to return to work in Ligasure group was $3.7 \pm 0.9$ days and in Open group was $8.3 \pm 1.2$ days $(\mathrm{t}=15.9, \mathrm{p}<0.01)$.

\section{Discussion:}

Sutureless technique utilizes 'Ligasure' tissue fusion, advanced monopolar, vessel sealing technology first introduced in 1998.It uses combination of pressure and energy to create vessel fusion which can withstand up to 3 times the systolic pressure and can seal vessels (up to $7 \mathrm{~mm}$ diameter), pedicles, tissue bundles, lymphatics. ${ }^{1}$ This technique denatures the body's collagen and elastin to both seal and divide with very high frequency current. This electro-surgical technique is effective in achieving hemostasis and is referred to as a 'vessel sealing system'. The energy is delivered only to the tissue grasped within the jaws of the hand held instrument with minimal spread of electrical or thermal energy to adjacent tissues. Complete coagulation of vessels and tissues is achieved with minimal charring in contrast to conventional diathermy. A computer controlled feedback loop automatically stops the flow of energy when coagulation of the vessels and mucosa is achieved.

Conventional Open hemorrhoidectomy is associated with significant pain-related complications such as urinary retention and constipation. Occasionally the operative field can become filled with blood, prolonging the duration of surgery; so meticulous hemostasis needs to be ensured to avoid postoperative hemorrhage. Ligasure ${ }^{\mathrm{TM}}$ hemorrhoidectomy has a major improvement in all these parameters over the conventional open technique.

In comparison with Open method, Ligasure ${ }^{\mathrm{TM}}$ hemorrhoidectomy had a shorter operating time (18.9 minutes vs 7.6 minutes, $\mathrm{p}$ value $<0.001$ ). The VAS pain score was lesser in Ligasure $^{\mathrm{TM}}$ than Open hemorrhoidectomy. Postoperative complications such as hemorrhage $(3.3 \%$ vs $33.3 \%)$ and urinary retention (3.3\% vs $46.6 \%)$ were all lower in the Ligasure ${ }^{\mathrm{TM}}$ group. The average duration of hospital stay (1.03 vs 2.1 days) and the median recovery time to work after surgery (8.3 days vs 3.7 days) was also less with Ligasure ${ }^{\mathrm{TM}}$. Compared with Open hemorrhoidectomy, the Ligasure ${ }^{\mathrm{TM}}$ method reduces post-operative pain and the requirement for parenteral analgesia because of minimal collateral thermal spread, limited tissue charring and absence of sutures. Pain during the first $24 \mathrm{~h}$ is particularly important as it can precipitate urinary retention and constipation.

Ligasure $^{\mathrm{TM}}$ hemorrhoidectomy with its numerous proven advantages of lesser pain score, lesser postoperative complications and lesser duration of surgery ${ }^{4}$ has the potential to make hemorrhoidectomy a day-care surgical procedure.

Many researchers have shown that hemorrhoidectomy via LigaSure is a safe and effective alternative to conventional hemorrhoidectomy with the benefits of less postoperative pain, ${ }^{5,6}$ less need for analgesics postoperatively, ${ }^{8,10,13-15}$ decreased operative time, ${ }^{11,12,14}$ faster return to normal activity ${ }^{8}$ less wound healing time, ${ }^{9,13}$ less intraoperative 
blood $\operatorname{loss}^{9,10,14}$ and short hospitalization. ${ }^{7}$ Gentile M. et al supported the use of this device as the treatment of choice in IV-degree haemorrhoids. ${ }^{6}$

A limitation of the present study is the small size of the sample and the limited follow-up. Long-term effectiveness of any operation for hemorrhoids is the most important concern for patients and surgeons. ${ }^{5}$ Thus, benefits of LigaSure sutureless technique as a long-term effective technique need to be further evaluated.

\section{Conclusion:}

Sutureless Hemorroidectomy is a safe and effective procedure as compared to Conventional Open MilliganMorgan Hemorroidectomy for Grade III and IV primary Hemorrhoids in terms of intraoperative and postoperative variables despite being a new instrument to the surgeon and an expensive instrument to the institution.

Patients derive greater short-term benefits: reduced intraoperative blood loss, operating time, and postoperative pain as well as earlier resumption of work.

\section{References:}

1. Lunniss $\mathrm{P}$, Nugent $\mathrm{K}$. The anus and anal canal. In: Williams NS, editor. Bailey \& Love's Short Practice of Surgery. $26^{\text {th }}$ ed. New York: CRC Press; 2013:1236-67.

2. Milligan ETC, Morgan CN, Jones LE, et al. Surgical anatomy of the anal canal and the operative treatment of hemorrhoids. Lancet 1937;2:1119-24.

3. Ferguson JA, Heaton JR. Closed hemorrhoidectomy. Dis Colon Rectum 1959;2:176-9.

4. Khanna R, Khanna S, Bhadani S, et al. Comparison of Ligasure Hemorrhoidectomy with Conventional Ferguson's Hemorrhoidectomy. Indian J Surg 2010;72:294-7.

5. Chen CW, Lai CW, Chang YJ, et al. Results of 666 consecutive patients treated with LigaSure hemorrhoidectomy for symptomatic prolapsed hemorrhoids with a minimum follow-up of 2 years. Surgery 2013;153:211-8.

6. Gentile M, Rosa MD, Carbone G, et al. LigaSure
Haemorrhoidectomy versus Conventional Diathermy for IV-Degree Hemorrhoids: Is It the Treatment of Choice? A Randomized, Clinical Trial. ISRN Gastroenterol 2011: 467258.

7. Milito G, Cadeddu F, Muzi MG, et al. Haemorrhoidectomy with Ligasure ${ }^{\mathrm{TM}}$ vs conventional excisional techniques: meta-analysis of randomized controlled trials. Colorectal Dis 2010;12:85-93.

8. Altomare DF, Milito G, Andreoli R, et al. Ligasure precise vs. conventional diathermy for MilliganMorgan hemorrhoidectomy: a prospective, randomized, multicenter trial. Dis Colon Rectum 2008;51:514-9.

9. Mastakov MY, Buettner PG, Ho YH. Updated metaanalysis of randomized controlled trials comparing conventional excisional haemorrhoidectomy with LigaSure for hemorrhoids. Tech Coloproctol. 2008;12:229-39.

10. Wang JY, Lu CY, Tsai HL, et al. Randomized controlled trial of LigaSure with submucosal dissection versus Ferguson hemorrhoidectomy for prolapsed hemorrhoids. World J Surg 2006;30:462-6.

11. Franklin EJ, Seetharam S, Lowney J, et al. Randomized, clinical trial of Ligasure vs. conventional diathermy in hemorrhoidectomy. Dis Colon Rectum 2003;46:13803 .

12. Chung YC, Wu HJ. Clinical experience of sutureless closed hemorrhoidectomy with LigaSure ${ }^{\mathrm{TM}}$. Dis Colon Rectum 2003;46:87-92.

13. Milito G, Gargiani M, Cortese F. Randomized trial comparing LigaSure haemorrhoidectomy with the diathermy dissection operation. Tech Coloproctol 2002;6:171-5.

14. PalazzoFF,FrancisDL,CliftonMA.Randomizedclinical trial of LigaSure versus open haemorrhoidectomy. Br J Surg 2002;89:154-7.

15. Thorbeck CV, Montes MF. Haemorrhoidectomy: randomized controlled clinical trial of Ligasure compared with Milligan-Morgan operation. Eur J Surg 2002;168:482-4. 